\title{
As Operações Ágata ${ }^{1}$
}

The Ágata Operations

Sophia Luiza Zaia ${ }^{2}$

\section{RESUMO}

O Plano Estratégico de Fronteiras, criado em 2011, visa o combate a ilícitos nas faixas de fronteira aumentando a presença do Estado brasileiro em pontos estratégicos. $O$ artigo versa sobre as sete Operações Ágata, que fazem parte do Plano, um esforço conjunto do Ministério da Defesa, das Forças Armadas e demais órgãos federais, estaduais e municipais.

Palavras-chave: faixa de fronteira; forças armadas; defesa.

\begin{abstract}
The Plano Estratégico de Fronteiras, created in 2011, aims to fight illicit activities throughout the border strip thus reinforcing the presence of the Brazilian state in strategic points. The article focuses on seven Operações Ágata, which are part of the Plano; a joint effort of the Ministry of Defense, the Armed Forces and other federal, state and local units.
\end{abstract}

Key-words: border strip; armed forces; defense.

O território brasileiro compreende 16.880 quilômetros de fronteira terrestre entre onze estados brasileiros e dez países. Objetivando reforçar a presença do Brasil e garantir a proteção necessária que tal dimensão fronteiriça exige, o governo federal, sob coordenação do vice-presidente da República, criou o Plano Estratégico de Fronteiras (PEF). O PEF foi instituído em 8 de junho de 2011, mediante o Decreto № 7.496 (2011), com seu Artigo 1ำ estabelecendo mobilizações “[...] para o fortalecimento da prevenção, controle, fiscalização e repressão dos delitos transfronteiriços e dos delitos praticados na faixa de fronteira brasileira", realizado por ação integrada de diversos ministérios e

\footnotetext{
${ }^{1}$ Artigo recebido em 25 de agosto de 2013 e aprovado para publicação em 23 de setembro de 2013.

2 Graduanda do curso de Relações Internacionais pela UNICURITIBA. Contato: sophizaia@hotmail.com, Curitiba, Brasil.
} 
órgãos de segurança pública, federais e estaduais, assim como a Secretaria da Receita Federal do Brasil (RFB) e as Forças Armadas (MINISTÉRIO DA DEFESA, 2011a).

O PEF compreende duas operações principais: a Sentinela e a Ágata. O propósito do presente artigo é fornecer um compêndio de cada Operação Ágata realizada até o momento devido a própria dificuldade em encontrar fontes que contemplem as sete operações num só registro. Diferentemente da Operação Ágata, a Operação Sentinela tem cunho permanente, sendo um trabalho das polícias Federal (PF), Rodoviária Federal e da Força Nacional de Segurança (FNS) sob coordenação do Ministério da Justiça. 0 presente artigo se ateve à Operação Ágata, pois a sua realização e sua própria natureza demonstram significante avanço na tentativa de superar os obstáculos que as Forças Armadas normalmente enfrentam na atuação conjunta, o que explica o caráter temporário das Operações Ágata e a escassa disponibilidade de fontes mais detalhadas.

A Operação Ágata é uma ação conjunta do Exército, Marinha e Aeronáutica, pela coordenação do Estado Maior Conjunto das Forças Armadas (EMCFA), sob responsabilidade do Ministério da Defesa (MD), e reflete os objetivos de presença e proteção fronteiriços do PEF. As Operações Ágata são realizadas em períodos prédeterminados, os países fronteiriços são comunicados previamente e convidados a auxiliar nas atividades, posicionando tropas ou observadores em seus territórios. Essas Operações contam com ações de vigilância e fiscalização do espaço aéreo, dos principais rios e estradas que dão acesso ao território nacional, proporcionando assistência médica e odontológica à população das faixas de fronteira (MINISTÉRIO DA DEFESA, 2011b).

De 5 a 20 de agosto de 2011, a Ágata 1 combateu crimes transfronteiriços e ambientais na região de Tabatinga e "Cachorro Grande", divisa com a Colômbia. Os objetivos da Ágata 1 incluíram: "a redução dos índices de criminalidade, a coordenação do planejamento e execução de operações militares e policiais, a intensificação da presença do Estado Brasileiro na região e o incremento do apoio à população residente na faixa de fronteira." Com o MD e das Forças Armadas, os órgãos federais e estaduais que participaram da Operação Ágata 1 foram: Polícia Federal, Instituto Brasileiro do Meio Ambiente e dos Recursos Naturais Renováveis (IBAMA), Secretaria da Receita Federal, Sistema de Proteção da Amazônia, Força Nacional de Segurança e Agência Brasileira de Inteligência (ESTADO-MAIOR CONJUNTO DAS FORÇAS ARMADAS, 2012a). 
O número de efetivos participantes da Operação Ágata 1 foram: 530 da Marinha do Brasil (MB), 1890 do Exército do Brasil (EB), 454 da Força Aérea Brasileira (FAB) e 170 de agências, totalizando 3.044 envolvidos. As ações cívico-sociais em números foram: 7.784 procedimentos, 419 procedimentos odontológicos, 2.086 procedimentos médicos, 1.458 vacinações e 32.369 entregas de remédios (MINISTÉRIO DA DEFESA).

A Ágata 2 foi realizada entre 12 e 16 de setembro de 2011, pelos Ministério da Defesa e da Justiça, nas fronteiras Sul e Centro-Oeste com o Paraguai, Argentina e Uruguai, entre Guairá e Chuí. As metas centrais da Operação Ágata 2 foram: "checagem de aeronaves e de combustível, atracadouros clandestinos, patrulha naval nas calhas dos rios, bloqueio e controle de estradas, reconhecimento especializado de fronteira, revista de veículos, embarcações, interceptação de aeronaves suspeitas" (DEFESANET, 2011).

A Operação Ágata 2 contou um total de 8.705 efetivos, sendo: 612 da MB, 6926 do EB, 473 da FAB e 694 de agências. As ações cívico-sociais totalizaram: 4531 procedimentos, 1463 procedimentos odontológicos, 2574 procedimentos médicos, 1458 vacinações e 30.124 remédios entregues (FORÇAS TERRESTRES, 2010).

A terceira edição da Operação Ágata, realizada de 22 de novembro a 7 de dezembro de 2011, abrangeu mais de seis mil quilômetros da Bahia Negra, no estado do Mato Grosso do Sul, até Tabatinga, no Amazonas, numa faixa de fronteira com o Paraguai, Bolívia e Peru, mantendo consonância com os objetivos das outras operações. A Operação Ágata 3 foi a última realizada no ano de criação do PEF.

Participaram da Ágata 3, junto com as Forças Armadas: Secretaria de Estado de Segurança Pública com a Polícia Militar, Polícia Civil, Perícia Oficial e Identificação Técnica, Centro Integrado de Operações Aéreas, Grupo Especial de Fronteira e Defesa Civil (DEVAUX, 2011; MARINHA DO BRASIL, 2011). A Operação contou com um total de 7.195 efetivos: 656 da MB, 5.296 do EB, 865 da FAB e 378 de outras agências. 0 desfecho das ações cívico-sociais foi: 15.221 procedimentos, 6.365 procedimentos odontológicos, 2.033 procedimentos médicos, 2.658 vacinações e 39.553 remédios entregues.

Durante essas três operações, foram empregados mais de 18 mil homens e mulheres, entre militares e agentes. Foram apreendidos: 59 motos, 20 caminhões, 465 kg de agrotóxicos, $332 \mathrm{~kg}$ de maconha, 19,5 kg de cocaína, 63 armas (duas de uso 
exclusivo das Forças Armadas), oito toneladas de explosivos e R\$345 mil e US\$ 260 mil em espécie. Quarenta e cinco mil quilômetros de rios e lagos foram patrulhados, com apreensão ou notificação de 46 embarcações. Foram destruídas três pistas de pouso clandestinas, desativados três garimpos ilegais (um deles em terras indígenas) e fiscalizadas e penalizadas cinco madeireiras ilegais (PLANALTO).

A primeira das Operações Ágata realizada em 2012, entre 2 à 17 de maio, a Ágata 4, ocorreu na região Norte do país na fronteira com a Venezuela, Guiana, Suriname e Guiana Francesa, uma extensão de mais de 5 mil quilômetros. 0 objetivo principal da Ágata 4, segundo o comandante da Operação, o general Villas Bôas, foi o de mapear tal área fronteiriça que é considerada um grande ponto cego para o Estado brasileiro, pois sua presença na cidade de Bonfim até o Oiapoque era praticamente inexistente. Durante a Ágata 4 as Forças Armadas atuaram juntamente com funcionários da Defesa Civil nas localidades situadas na margem dos rios Negro e Solimões atingidas frequentemente por enchentes que desalojam milhares de cidadãos (FORÇAS TERRESTRES, 2012).

Dentre os órgãos e agências participantes da Ágata 4 estavam: as Forças Armadas, o IBAMA, o Departamento Nacional de Produção Mineral (DNPM), a Polícia Federal, a FNS, a Agência Nacional de Aviação Civil (ANAC), a RFB entre outras agências (FORÇA AÉREA BRASILEIRA, 2012) (FORÇA NAVAL, 2012).

O número de efetivos participantes da Operação Ágata 4 foi: 3.324 da MB, 3.843 do EB, 1.034 da FAB e 303 de agências, totalizando 8.304 efetivos. 0 número de ações cívico-sociais foi de: 20.928 procedimentos, 1.629 procedimentos odontológicos, 8.507 procedimentos médicos, 1.458 vacinações e 53.314 remédios entregues.

A Ágata 5 ocorreu de 6 a 20 de agosto de 2012 na faixa de fronteira Sul e Oeste com a Argentina, Uruguai e Paraguai entre as cidades de Chuí, Rio Grande do Sul, até Corumbá, Mato Grosso do Sul, uma área que abrange cerca de $3.900 \mathrm{~km}$. Os objetivos e meios preventivos e repressivos empregados na Ágata 5 foram correspondentes com aqueles das Operações Ágata anteriores. A Ágata 5 mobilizou civis e militares no bloqueio da linha internacional que avança até 150 quilômetros para dentro do país.

Os principais órgãos atuantes na Ágata 5 foram: Ministério da Justiça, Ministério das Relações Exteriores, Ministério das Minas e Energia, Ministério do Meio Ambiente, 
Fundação Nacional do Índio (Funai), além de órgãos estaduais e municipais dos estados evolvidos na Operação (ESTADO-MAIOR CONJUNTO DAS FORÇAS ARMADAS, 2012b).

Participaram 19.806 efetivos na Ágata 5, sendo 2.024 da MB, 8.628 do EB, 8.520 da FAB e 634 de agências. As ações cívico-sociais em números foram: 7.954 procedimentos, 4.725 procedimentos odontológicos, 3.598 procedimentos médicos, 273 vacinações e 25.662 entregas de remédios.

A Operação Ágata 6, realizada de 9 a 22 de outubro de 2012 na faixa de fronteira Oeste e Noroeste do país com o Peru e a Bolívia, abrangeu os estados do Acre, Rondônia, Mato Grosso e Mato Grosso do Sul. Entre as localidades de Forte Coimbra (MS) e Gibraltar (AC), a extensão fronteiriça foi de aproximadamente $4.200 \mathrm{Km}$.

A Ágata 6 foi a última Operação Ágata realizada no ano de 2012. A ação conjunta das Forças Armadas com demais ministérios e órgãos federais, estaduais e municipais resultaram na apreensão de: 67 veículos (automóveis, motos, caminhões, ônibus), 201 embarcações, 3,7 toneladas de drogas ilícitas (maconha, cocaína, etc.) avaliadas em R\$ 2.132.682,00; 12 detenções e prisões, 15 armamentos, 758 cartuchos de munições de vários calibres (ESTADO-MAIOR CONJUNTO DAS FORÇAS ARMADAS, 2012c).

A Operação Ágata 6 teve participação total de 13.162 efetivos, sendo: 4.044 da MB, 3.219 do EB, 5.646 da FAB e 253 de agências. As ações cívico-sociais totalizaram: 3.299 procedimentos, 3.706 procedimentos odontológicos, 10.684 procedimentos médicos, 0 vacinações e 14.219 remédios entregues (MINISTÉRIO DA DEFESA, 2013a).

Ao longo das seis Operações Ágata, 11 estados, 122 cidades e 588 municípios foram abrangidos, 319.365 veículos e 5.581 embarcações foram inspecionados, 11.801 $\mathrm{kg}$ de drogas e 19,8 toneladas de explosivos foram apreendidos, e recuperados cerca de R\$ 243 mil em crimes de contrabando ou descaminho (MINISTÉRIO DA DEFESA, 2013a).

A Operação Ágata 7, ocorrida de 18 de maio a 6 de junho deste ano, abrangeu cerca de 16.886 quilômetros de fronteira com 10 países sul-americanos (Guiana Francesa, Guiana, Suriname, Venezuela, Colômbia, Bolívia, Peru, Paraguai, Argentina e Uruguai) e 11 estados brasileiros (Amapá, Pará, Roraima, Amazonas, Acre, Rondônia, Mato Grosso, Mato Grosso do Sul), entre o Oiapoque e o Chuí, com número aproximado de 25 mil militares. A Ágata 7, com os mesmos objetivos das anteriores, ocorreu às 
vésperas da Copa das Confederações, evento realizado nas cidades-sede: Belo Horizonte (MG), Brasília (DF), Fortaleza (CE), Recife (PE), Rio de Janeiro (RJ) e Salvador (BA).

Ao final da Operação Ágata 7, a apreensão de drogas teve balanço recorde pelo EMCFA: 25,342 toneladas de maconha e 657 quilos de cocaína, crack e haxixe. Foram apreendidos 4,9 toneladas de explosivo numa empresa na região de Maringá (PR) e na região Sul do país foram apreendidos 4 fuzis 762. Em São Gabriel da Cachoeira (AM), 10 pessoas, entre elas políticos e empresários, foram presos acusados de pedofilia e prostituição de indígenas; 4,5 mil metros cúbicos de madeira foram apreendidos; as forças militares e a Polícia Federal conseguiram neutralizar uma das três safras de coca colhidas anualmente no Peru, numa região de aproximadamente 30 mil hectares, contando com o apoio e mobilização das tropas militares do Peru e da Colômbia.

Com o auxílio de agências reguladoras, como a ANAC, Agência Nacional do Petróleo, Agência Nacional de Telecomunicações, DNPM, IBAMA, Funai, Instituto Chico Mendes de Conservação da Biodiversidade e Capitanias de Portos, foram inspecionadas 17.587 embarcações e vistoriados 267.590 veículos e 17.165 pedestres.

O balanço dos procedimentos cívico-sociais foi: 28.216 atendimentos médicos, 35.966 atendimentos odontológicos e 55.160 medicamentos distribuídos e as atividades de prevenção de saúde atenderam 68.726 pessoas (MINISTÉRIO DA DEFESA, 2013b).

As sete Operações Ágatas realizadas até o momento demonstram evolução contínua nos esforços do PEF, pois a Ágata 7 revelou-se um avanço não apenas no combate a ilícitos como também em ações voltadas à sociedade civil e sua assistência na faixa de fronteira. 0 general José Carlos De Nardi, chefe do EMCFA, destacou "em nome do ministro da Defesa, Celso Amorim, quero agradecer pela participação, pelo empenho e pela operacionalidade. Tivemos um sucesso imenso na operação de fronteira que constituiu um dos eixos dos grandes eventos" (MINISTÉRIO DA DEFESA, 2013b).

\section{Referências Bibliográficas}

DECRETO, 2011. DECRETO № 7.496, DE 8 DE JUNHO DE 2011. Disponível em: <https://www.defesa.gov.br/operacao-agata/arquivos/dec7496_8_jun_11.pdf>. Acesso em: 25/05/2013. 
DEFESANET. PEF - Operação Ágata 2. Publicado em: 16/09/2011. Disponível em: <http://www.defesanet.com.br/fronteiras/noticia/2806/PEF---Operacao-Agata-2>.Acesso em: 24/05/2013.

DEVAUX, Sílvia. Plano estratégico de fronteira. Segurança estadual reforça ação da Operação Ágata III na fronteira de MT. Publicado em: 21/11/2011. Estado de Mato Grosso. Casa militar. Disponível em: <http://www.casamilitar.mt.gov.br/TNX/conteudo.php?sid=44\&cid=2156>. Acesso em: 26/05/2013.

ESTADO-MAIOR CONJUNTO DAS FORÇAS ARMADAS (2012a). Portal de Operações do Ministério da Defesa em Ações Conjuntas. Disponível em: <http://www.operacoes.defesa.mil.br/web/guest/operacao-agata-1>. Acesso em: $25 / 05 / 2013$.

ESTADO-MAIOR CONJUNTO DAS FORÇAS ARMADAS (2012b). Portal de Operações do Ministério da Defesa em Ações Conjuntas. Vídeos da operação. Disponível em: <http://www.operacoes.defesa.mil.br/web/guest/operacao-agata-5>. Acesso em: $25 / 05 / 2013$.

ESTADO-MAIOR CONJUNTO DAS FORÇAS ARMADAS (2012c). Portal de Operações do Ministério da Defesa em Ações Conjuntas. Disponível em: <http://www.operacoes.defesa.mil.br/web/guest/operacao-agata6\#.UaMe9bU3uuI>. Acesso em: 26/05/2013.

FORÇA AÉREA BRASILEIRA ÁGATA 3 - Operação mobiliza aeronaves da Força Aérea na região de fronteira. Publicado em: 21/11/2011. Disponível em: <http://www.fab.mil.br/portal/capa/index.php?mostra=9247>. Acesso em: 26/05/2013.

FORÇA AÉREA BRASILEIRA. FORÇA AÉREA FM - Ouça entrevista com o Comandante da Força Aérea na Operação Ágata 4. Publicado em: 02/05/2012. Disponível em: <http://www.fab.mil.br/portal/capa/index.php?mostra=10825>. Acesso em: $25 / 05 / 2013$.

FORÇA NAVAL. Força Naval Componente apresenta resultados das ações realizadas na Operação “Ágata 4". 2012. Disponível em: 
<http://www.mar.mil.br/nomaronline/noticias/14052012/05.html>. Acesso em: 26/05/2013.

FORÇAS TERRESTRES. Operação Ágata 4 - Entrevista coletiva divulga operação na fronteira Norte. Publicado em: 04/05/2012. Disponível em: $<$ http://www.forte.jor.br/page/3/?s=opera\%C3\%A7\%C3\%A3o+\%C3\%A1gata+4>. Acesso em: 25/05/2013.

FORÇAS TERRESTRES. Publicado em: 16/09/2011. Disponível em: <http://www.forte.jor.br/?s=opera\%C3\%A7\%C3\%A3o+\%C3\%A1gata+>. Acesso em: 26/05/2013.

MARINHA DO BRASIL. Marinha do Brasil na Operação "Ágata 3". Publicado em: 21/11/2011. Disponível em: <http://www.mar.mil.br/nomaronline/noticias/04012012/03.html>. Acesso em: 26/05/2013.

MINISTÉRIO DA DEFESA (2011a). Operação Ágata. Disponível em: <https://www.defesa.mil.br/operacao-agata/operacoes-agata.html>. Acesso em $25 / 05 / 2013$.

MINISTÉRIO DA DEFESA (2011b). Operação Ágata- Plane Estratégico de fronteiras. Disponível em: <https://www.defesa.mil.br/operacao-agata/planoestrategico.html>. Acesso em: 26/05/2013.

MINISTÉRIO DA DEFESA (2013a). Operação Ágata 7. Disponível em: <https://www.defesa.mil.br/operacao-agata/entenda-operacao.html>. Acesso em: $25 / 05 / 2013$.

MINISTÉRIO DA DEFESA (2013b). Notícias sobre a Operação Ágata. Disponível em: <http://www.defesa.gov.br/operacao-agata/noticias.html>. Acesso em: 19/06/2013.

MINISTÉRIO DA DEFESA. Operação Ágata - Edições Anteriores. Disponível em: <https://www.defesa.mil.br/operacao-agata/edicoes-anteriores.html>. Acesso em: $26 / 05 / 2013$. 